\title{
Spillover of Pro-environmental Behaviour
}

\author{
Caroline Verfuerth* \\ Sheffield University Management School, University of Sheffield \\ 169-171 Northumberland Road, Sheffield, S10 1DF \\ email: cverfuerth@sheffield.ac.uk \\ phone: +44(0)114 2223232 \\ * Corresponding author \\ Dr Diana Gregory-Smith \\ Birmingham Business School, University of Birmingham \\ Edgbaston Park Road, Birmingham, B15 2TY \\ email: d.gregory-smith@bham.ac.uk \\ phone: +44(0)121 4158194
}

\subsection{Introduction to the spillover effect}

The aim of this chapter is threefold. Firstly, the chapter aims to introduce the term 'spillover' and its different conceptualisation, as well as providing an overview of current research developments. This chapter will overall provide the reader both a broad understanding of the different concepts of the spillover effect alongside its implications for environmentally friendy behaviours in the workplace. Secondly, the chapter aims to give an overview of underlying factors that influence spillover and a discussion of how the spillover effects might influence social marketing campaigns and behavioural change programmes that promote pro-environmental behaviours in organisations. Finally, the chapter aims to assess the methodological approaches used to investigate spillover effects, inclusive of quantitative, qualitative and mixed methods.

The psychological concept of spillover could be simply understood as the flow and propulsion of cognitive thoughts, emotions or actions from one area to another. In relation to the latter aspect, Nillson et al. (2016: 1) consider that "the spillover effect proposes that engaging in one behavior affects the probability of engagement or disengaging in a second behaviour”. The idea of the spillover effect is not new and has been applied in a number of areas such as knowledge (Acs et al., 2009), emotional conflicts between the workplace and the family (Grunberg et al., 1998; Westman, 2002) and health behaviour (Dolan and Galizzi, 2014). More recently, research in the fields of ethical marketing and environmental psychology has been investigating the spillover phenomenon in the context of sustainable lifestyles; here an increasing interest in understanding secondary behaviour 
effects of pro-environmental behaviours on other behaviours has emerged. In this area, the concept of spillover has been used to explore the link between different pro-environmental behaviours and between pro-environmental behaviours in different contexts. For example, a positive spillover has been found between individuals' energy saving at home and openness to more generic low carbon policies such as such as infrastructural changes and subsidies for reducing household carbon emissions (Steinhorst and Matthies, 2016).

While following the same line of thinking, three approaches to conceptualising spillover of proenvironmental behaviour have emerged. One strand of research conceptualises spillover as the effect that past pro-environmental behaviour has on the likelihood of an individual engaging in other future pro-environmental behaviours (e.g. Lauren et al., 2016; van der Werff et al., 2014). For instance, an employee who always cycles to work and has done so in the past might also try to save energy at work by switching off his/her computer at the end of the working day. Another strand of research conceptualises spillover as the effect a behaviour change intervention may have on pro-environmental behaviours that were not the specific target of a given intervention (Truelove et al., 2014). For example, when an energy saving programme encourages employees to conserve energy at work, a spillover effect occurs if the increased energy saving behaviour of the employees has a knock-on effect on other pro-environmental behaviours such as commuting to work or recycling. This conceptualisation of spillover presumes that a behaviour change intervention is needed to trigger spillover. A third strand of spillover research suggests that the commonly used conceptualisations of spillover fall short of acknowledging individual agency, that is individuals' active choice to engage in a behaviour (Uzzell and Räthzel, 2013). Uzzell and Räthzel (2013) argue that individuals actively shape, adjust and negociate their behaviours and social environments, and they are also shaped by their environments. This view is contrary to the other conceptualisaitons spillover that often imply an 'automatic' spillover of a pro-environmental behaviour to other pro-environmental behaviours or settings. As a consequence, Uzzell and Räthzel (2013) prefer the term 'border crossing', which particularly refers to spillover effects between social contexts (e.g. work and home); for more details see section 3.1.

Some researchers also suggest that a distinction should be made between behavioural spillover, contextual and temporal spillover (Nilsson et al., 2016). Behavioural spillover describes spillover effects across behaviours (Nilsson et al., 2016); e.g. from energy conserving behaviours to waste management behaviours. Contextual spillover - sometimes refered to spillover between settings (Littleford et al., 2014) - refers to spillover effects of pro-environmental behaviours between different social and physical contexts or settings (e.g. between work and home). Temporal spillover incorporates the time component and refers to the effect a pro-environmental behaviour at time T1 has on a pro-environmental behaviour at a later time T2 (Nilsson et al., 2016). 
Previous research has mostly focussed on behavioural spillover with the aim to understand and explain how pro-environmental behaviours are connected and future behaviours might be promoted (Dolan and Galizzi, 2015; Truelove et al., 2014). However, temporal and behavioural spillover are often not differentiated. Cross-contextual spillover research, on the other hand, aims to understand how a pro-environmental behaviour in one context, such as the workplace, may spillover to other settings like the home or leisure. People spend a large amount of their day-to-day time within these settings (Klade et al., 2013) and this is why cross-contextual spillover, in addition to behavioural spillover, can provide implications for promoting sustainable lifestyles.

\subsection{Positive spillover \& negative spillover}

Spillover of pro-environmental behaviour can broadly be divided in two types: positive spillover and negative spillover (Thøgersen, 1999). Positive spillover describes the positive effect a proenvironmental behaviour has on other pro-environmental behaviours (Thøgersen and Ölander, 2003) or environmental attitudes (Lacasse, 2016). This includes pro-environmental behaviours and attitudes in a different context or at a different time point, and may be triggered by a behaviour change intervention or occur organically. For example, when a person purchases organic food he/she might subsequently purchase products with less packaging. This instance would be described as positive spillover. Conversely, negative spillover refers to subsequent behaviour that is contrary to previous pro-environmental behaviours (Truelove et al., 2014; Thøgersen and Ölander, 2003). Thus, negative spillover describes instances when a pro-environmental behaviour can be linked to a decrease in other pro-environmental behaviours or an increase in environmentally damaging behaviours. An example could be a situation when a person's decision to switch to organic food might lead subsequently to an increase in their water consumption. Some studies suggest that positive and negative spillover may occur simultaniously (Klöckner et al., 2013; Lacasse, 2016), which leads to an observed 'no net' spillover, that is when positive and negative spillover average out. For instance, a recent study by Lacasse (2016) found that when people are reminded of their past pro-environmental behaviours a very small total spillover effect occurred. This effect was mediated by environmental self-identity and guilt, which explained a positive and a negative spillover path, respectively (Lacasse, 2016). Thus, Lacasse's (2016) findings indicate that both positive and negative spillover occur simultaniously, but in sum - averaged out to a small spillover effect.

The effect described above as positive spillover can be found in the literature under a variety of terms such as catalyst behaviour (Austin et al., 2011), virtuous escalator effect (Thøgersen and Crompton, 2009), foot-in-the-door effect (Thøgersen and Noblet, 2012), or carryover effect (Lerner et al., 2004; Dolan and Galizzi, 2015). The idea of catalyst behaviour is that certain environmentally-friendly behaviours have a knock-on effect and may cause broader behaviour change (Austin et al., 2011). The virtuous escalator effect refers to the assertion that one small environmentally-friendly behaviour can spillover to other, more ambitious and environmentally significant behaviours (Thøgersen and 
Crompton, 2009). Similarly, the foot-in-the-door effect (Burger, 1999) is based to the idea that an easy behaviour increases the chances that people will also perform a second, more difficult behaviour. For example, a campaign promoting simple behaviours such as switching off lights in offices would then have a positive spillover effect on other, more difficult pro-environmental behaviours such as reducing the temperature in offices in the winter or commuting to work by public transport instead of by car. The carryover effect, on the other hand, describes emotional spillover that occurs long after the initial behaviour took place and which affects a subsequent behaviour (Lerner et al., 2004).

The negative spillover effect, or special cases of it, can be found under terms such as rebound effect (for an overview see Sorrell et al., 2009) or single action bias (Dolan and Galizzi, 2015). The rebound effect describes an increase of energy demand after energy efficiency was improved (e.g. increase in distances travelled after purchase of a fuel efficient car) which means the savings that could be achieved are not realised in full (Peters et al., 2012). The rebound effect is specific to energy behaviours and often discussed in relation to the introduction of an energy-efficient technology whilst only addressing energy demand, not pro-environmental behaviours in general. The single action bias refers to the phenomenon that people change one - often relatively insignificant - behaviour but do not take on any further behaviours (Truelove et al., 2014). Taking on a single action reduces peoples' feeling of worry; as a result of this, individuals do not take on any further pro-environmental actions (Weber, 2006) or compensate for their behaviours (Gregory-Smith et al., 2015).

\subsection{Psychological theories explaining the spillover effect}

Both positive and negative spillover effects are frequently explained with a number of psychological theories. While these theories have been established in different contexts, they are frequently used to explain spillover of pro-environmental behaviours. Two of the most commonly used psychological theories to explain positive spillover are the cognitive dissonance theory (Festinger, 1957) and the self-perception theory (Bem, 1972). Negative spillover is often explained with moral licencing (Truelove et al., 2014), compensatory green beliefs (CGBs; Kaklamanou et al., 2013), and neutralisation theory (Sykes and Matza, 1957).

\subsubsection{Cognitive dissonance and self-perception theory}

According to cognitive dissonance theory (Festinger, 1957) people experience discomfort when holding two contrasting cognitions and are motivated to reduce the psychological uneasiness they experience. This can be achieved in a number of ways, including changing attitudes, behaviours, externalising responsibility or reducing the importance of dissonant elements (Gregory-Smith et al., 2013). In the pro-environmental context, this means a person holding pro-environmental views but acting unsustainably will experience a psychological discomfort. This may be reduced by acting in an environmentally-friendly way (Thøgersen, 2004). Therefore, the need for consistency might lead to positive spillover between environmentally-friendly behaviours and between settings. Inconsistent 
pro-environmental behaviours (sometimes refered to as the attitude behaviour gap; Kollmuss and Agyeman, 2002) are often explained with the neutralisation theory (Sykes and Matza, 1957). For instance, negative spillover and a lack of positive spillover can arise when a person aims to overcome cognitive dissonance by using neutralisation techniques including denial and justification (Chatzidakis et al., 2006) or CGBs (Kaklamanou et al., 2013). On the other hand, self-perception theory (Bem, 1972) posits people infer their identities and attitudes from past behaviours. According to this, people align their cognitions (e.g. attitudes, values, identity) with their observed past behaviour, particularly in ambiguous situations (Austin et al., 2011). Hence, acting pro-environmentally leads people to reaffirm their 'green' identity, which subsequently motivates them to act in line with their identity and cognitions in the future. Self-perception theory (Bem, 1972) suggests that past pro-environmental behaviours lead to more pro-environmental behaviours which are connected through one's selfperception; hence, positive spillover can occur (van der Werff et al., 2014a).

\subsubsection{Moral licencing and compensatory green beliefs}

Moral licencing describes the effect by which people, who initially behaved morally (e.g. environmentally friendly), subsequently display immoral behaviours as a result of feeling licensed to do so (through their previously moral behaviour) or vice versa (Blanken et al., 2015). A quasiexperimental field study showed that donating to a charity subsequently led to lower environmental intentions (Meijers et al., 2015). Similarly, negative spillover in an environmental context can be explained by CGBs (Kaklamanou et al., 2013). CGBs refer in particular to people’s belief that proenvironmental behaviour can compensate for more negative environmental behaviour; e.g. purchasing organic food as a compensation for flying abroad on holidays (Gregory-Smith, et al., 2013; Kaklamanou et al., 2013). In a qualitative study Hope et al. (2017) found that people experienced psychological benefits from holding CGBs as it reduced their negative feeling (e.g. guilt) towards negative environmental behaviour. This in turn made them feel more positive about their overall environmental impact (Hope et al., 2017). These findings indicate that CBGs are sometimes used to justify a person’s environmentally damaging behaviour.

\subsection{Emotional carryover effect}

The concept of carryover or spillover of emotions and their influence has originated in the psychology literature. Han et al. (2007: 158) have developed the appraisal-tendency framework, which illustrates "how and why specific emotions carry over from past situations to colour future judgments and choices”. The framework distinguishes between integral emotions (i.e. emotions relevant to present decisions) and incidental emotions (i.e. emotions irrelevant to present choices but which influence them). It is precisely the latter category that has a carryover effect, mostly unconscious, into other decisions and contexts than where they originated. For example, sadness experienced in a personal context could influence one's shopping or eating behaviours. 
While the emotional spillover effect has been examined in contexts such as economic decisions (e.g. buying decisions, assessment of risk - Lerner et al., 2004) and in relation to negative emotions (e.g. sadness, disgust, anger - Winterich, Han and Lerner, 2010 ), this concept is under-researched in the pro-environmental literature. This has happened despite some studies pointing out the influence integral emotions have on individuals' pro-environmental decisions (e.g. Carrus et al., 2008; GregorySmith et al., 2013; Lacasse, 2016). Evidence for this potential spillover of emotions across contexts, including pro-environmental behaviours, comes from the field of organisational psychology where research has identified a spillover of behaviours and emotions between the work and home (e.g. happiness - Rodríguez-Muñoz et al., 2014; aggression and conflicts - Sanz-Vergel et al., 2015; exhaustion and satisfaction - Lee et al., 2016).

Similarly, a stream of research looking at ethics and morality hints at the potential negative spillover of emotions. Particularly, it is believed that moral behaviours will generate positive emotions, that in some cases and for some individuals, will influence negatively other decisions with a moral valence; i.e. they will reduce the negative emotions that might be anticipated or arise from engaging in an immoral behaviour (Merritt et al., 2010). A similar line of thought could be applied to proenvironmental behaviours for those individuals who perceive these behaviours as having a moral dimension. Alternatively, research has pointed out that positive moral behaviours such altruism can also carry over from one domain to another. For example, Laury and Taylor (2008) have demonstrated altruism spillover across contexts; in particular, they showed that altruism in the laboratory setting can spread to decisions related to naturally occurring public goods.

\subsection{Spillover in the workplace}

Organisations show an increasing interest in sustainability, which is driven both by cost and CSR considerations (Young et al., 2013). However, unlike at home, at work employees face additional barriers towards acting pro-environmentally (e.g. sharing electronic devices with colleagues when trying to conserve energy) and financial interests to save energy or water may differ (Carrico and Riemer, 2011). While antecedents and motivators for pro-environmental household behaviours have been widely investigated (e.g. Abrahamse et al., 2005; Steg and Vlek, 2009), more recently, research aims to understand and promote pro-environmental behaviour at work (e.g. Gregory-Smith et al., 2015). In addition to the home, the workplace is one of the main 'microenvironments' where people spend most of their day-to-day time (Cox et al., 2012), which is why the workplace is an important setting for promoting sustainable lifestyles. Thus, potential spillover effects between behaviours at home and work as well as spillover between the two settings has started to attract research interest recently (Muster, 2011). Nonetheless, spillover effects both between behaviours and between settings 
are under-researched and need further understanding as this would help promote sustainable lifestyles within and across peoples' life-domains.

\subsection{Spillover between pro-environmental behaviours in the workplace}

The growing interest in the employees’ pro-environmental behaviour (e.g. recycling, energy saving), which can be defined as "scalable actions and behaviours that employees engage in that are linked with and contribute to or detract from environmental sustainability” (Ones et al., 2012: 87). Work in this area has led to the development of a classification of employee green behaviour, called the 'green five taxonomy'(Ones and Dilchert, 2012). This classification includes five meta-categories of employee green behaviour: 1) avoiding harm, 2) conserving, 3) working sustainably, 4) influencing others, and 5) taking initiative.

According to Ones and Dilchert's (2012) taxonomy (see taxonomy detatils in another chapter in this handbook), spillover of pro-environmental behaviour at work can occur within a specific category (e.g. spillover from reusing to recycling in the 'conserving' category) or between categories (e.g. from the 'conserving' category to 'taking initiative' category). For instance, reducing energy use at work by switching off electrical devices instead of standby, which would be in the category 'conserving', might have a spillover effect on recycling behaviour, also in the category 'conserving'. In line with this, a study investigating the effect of feedback on residential water, Tiefenbeck et al. (2013) found that while people reduced their water consumption, they also increased their electricity consumption. This suggests a negative spillover effect within the 'conserving' category. Although the study was conducted in the residential and not the work context, it is possible that similar effects occur in the workplace context between and within behaviour categories. For instance, reducing energy use at work might have a positive spillover effect on encouraging and supporting others from the category ‘influencing others’ or it might have a negative spillover effect on recycling behaviour.

\subsubsection{Similarities between behaviours in the workplace}

An important aspect of the spillover between the home and workplace contexts is the (lack of) similarities between behaviours. Empirical evidence suggests that spillover is more likely between behaviours that are perceived as being similar as opposed to dissimilar (Margetts and Kashima, 2017; Littleford et al., 2014). Likewise, in relation to workplace spillover, it can be assumed that perceived similarity of pairs of pro-environmental behaviours (e.g. taking public transport to work and buying environmentally labelled brands) increases the consistency of engaging in these activities (Thøgersen, 2004), leading to positive spillover between similar behaviours. Littleford et al. (2014) investigated spillover between office and household settings and found correlations between behaviours that shared the same type of equipment (i.e. computer) or the same triggers or behaviour settings (i.e. leaving the room). Despite not finding evidence to support the existence of positive spillover across settings, they concluded that spillover across settings would be most likely when categories such as 
type of equipment or the behavioural trigger were similar (Littleford et al., 2014). Similarly, Margetts and Kashima (2017) found that pro-environmental behaviours that require the same resources (e.g. money or time) are also perceived as more similar and thus more likely to spillover. These studies suggest that perceived similarity between pro-environmental behaviours is a relevant aspect to consider when researching spillovers in relation to the workplace context but it is also a complex aspect to investigate.

Additionally, Lanzini and Thøgersen (2014) differentiate between functional and symbolic similarities, in the context of spillover from 'green' purchasing behaviour to other pro-environmental behaviours. Lanzini and Thøgersen (2014) propose that symbolic similarities of behaviours might have an effect on consistency-based spillover, whereas functional similarities between behaviours might have an effect on knowledge-based spillover. Although their study does not focus on the workplace setting, the differentiation between functional and symbolic similarities has implications for spillover of proenvironmental behaviours in the workplace as well. Similarities can act either as drivers or as barriers to positive spillover between behaviours. For instance, the relevance of similarities of behaviours is somewhat reflected in Ones and Dilchert's (2012) classification of employee green behaviour. Specifically, for employee pro-environmental behaviours this means that positive spillover is more likely to occur between categories of behaviours such as 'conserving' and 'working sustainably' or between 'influencing others' and 'taking initiatives'; and between specific behaviours that are perceived similar, such as turning off lights and turning off electric devices (rather than between behaviours perceived as dissimilar such as recycling and reducing meat consumption).

\subsubsection{Easy and difficult behaviours in the workplace}

Spillover from 'easy' to 'difficult' pro-environmental behaviours and vice-versa is often discussed as a potential direction for positive spillover. According to the foot-in-the-door effect (Burger, 1999), 'simple and painless' behaviours might open the door to more difficult pro-environmental behaviours (Thøgersen and Crompton, 2009). In support of this, a study on water conserving behaviours suggests that foot-in-the-door effects may occur from easy to more difficult pro-environmental behaviours but only when people's self-efficacy to perform such behaviours is high (Lauren et al., 2016). The footin-the-door effect (Burger, 1999) and people’s preference for consistent behaviour (Cialdini et al., 1995) can have relevant implications for promoting pro-environmental behaviours in the workplace. For instance, encouraging employees to conserve energy in their workplace may lead to a higher acceptance of more radical 'green' policy changes in the organisation. Empirical support for this was found by a number of studies suggesting that encouraging people to engage in pro-environmental behaviours leads to a greater acceptance of green policies (low carbon policy acceptability Steinhorst and Matthies, 2016; acceptance of wind power - Thøgersen and Noblet, 2012). In the contrary, some studies also found that easy and costless behaviours (e.g. recycling) lead to a decreased acceptance of green policies and negative spillover (Truelove, 2016; Gneezy et al., 2012). 
Nonetheless, the assumption that positive spillover will occur simply by nudging people to engage in simple and easy pro-environmental behaviours is often implicitly made by campaigners and policy makers in the hopes that campaigns and policies that promote easy behaviours spillover to encourage more difficult and environmentally significant behaviours (Defra, 2008). Thus, although some empirical evidence suggests that a positive spillover effect from easy to more difficult proenvironmental behaviours may occur, this needs to be treated with caution (for an overview of the limitations of spillover in environmental campaigning see Thøgersen and Crompton, 2009).

\subsection{Theoretical frameworks of behavioural spillover in the workplace}

To gain a better and more comprehensive understanding of positive, negative but also a lack of spillover, theoretical frameworks have been developed. In contrast to the theories that are used to explain spillover effects, these theoretical frameworks have been developed to explain spillover effects between pro-environmental behaviours taking into account previous empirical findings and theoretical considerations.

\subsubsection{Decision mode and behavioural characteristics in the workplace context}

Truelove et al. (2014) proposed a conceptual framework for spillover that focuses on the decision making processes involved when acting environmentally-friendly. They define spillover as the effect of an intervention on subsequent behaviours that was not targeted by the intervention (Truelove et al., 2014; see also conceptualisations of spillover in section 1). Truelove et al. (2014) propose that the direction of the spillover effect is based on the decision making style which leads to different paths of secondary pro-environmental behaviours; that is positive, negative or no net spillover. Positive spillover occurs when a pro-environmental behaviour increases the likelihood of performing another pro-environmental behaviour, while negative spillover occurs when the initial pro-environmental behaviour leads to a reduction of pro-environmental behaviours (Truelove et al., 2014). No net spillover refers to an instance when positive and negative spillover average out, which means that overall no spillover occurs (Truelove et al., 2014). The framework identifies two main factors that influence spillover: (1) decision mode (different ways of decision making) and (2) attribution of one's behaviour after the decision process (Truelove et al., 2014). Three types of decision making are proposed: calculation based, negative affect based, role based; the first leads to no net spillover, the second leads to negative spillover, and the latter leads to positive spillover (Truelove et al., 2014).

According to the framework, a calculation based decision leads to no net spillover that is influenced by external attribution (e.g. incentive for previous pro-environmental behaviour) or difficulty of the behaviour, which would increase the likelihood of negative spillover (Truelove et al., 2014). An affect based decision is more likely to lead to negative spillover mediated by reduced negative affect (e.g. fear, guilt; Truelove et al., 2014). The link between negative affect based decision making and negative spillover draws on moral licencing theory (Blanken et al., 2015) and single action bias 
(Dolan and Galizzi, 2015). Role based decision making, on the other hand, has a positive effect on identity reinforcement, which then increases the likelihood for positive spillover (Truelove et al., 2014). A decision made based on a role enhances the identification with the role and the social identity that is associated with it, e.g. a decision made in the role of a factory worker reinforces the identity as a factory worker as well, which is here called identity reinforcement (Truelove et al., 2014). Identity reinforcement can be amplified with internal and external attribution and difficulty of the behaviour(Truelove et al., 2014). For example, if an employee attributes her/his energy saving behaviour at work to her/his abilities of being a pro-environmental person (internal attribution) this will reinforce the employee's environmental identity (Truelove et al., 2014). On the other hand, if an employee attributes her/his energy saving behaviour at work to external factors (external attribution), such as financial incentives the employer provides for their staff to save energy, this decreases the employee's intrinsic motivation and the perception of her/him being a pro-environmental person (Truelove et al., 2014). When then the financial incentive is taken away, the employee is no longer likely to engage in the energy saving behaviour and potentially any other pro-environmental behaviours at work - negative spillover occurs (Truelove et al., 2014). The link between identity reinforcement and positive spillover is amplified when the subsequent behaviour is similar to the previous behaviour, but weakened when the subsequent behaviour is difficult (Truelove et al., 2014). See Figure 1 for a simplified illustration.

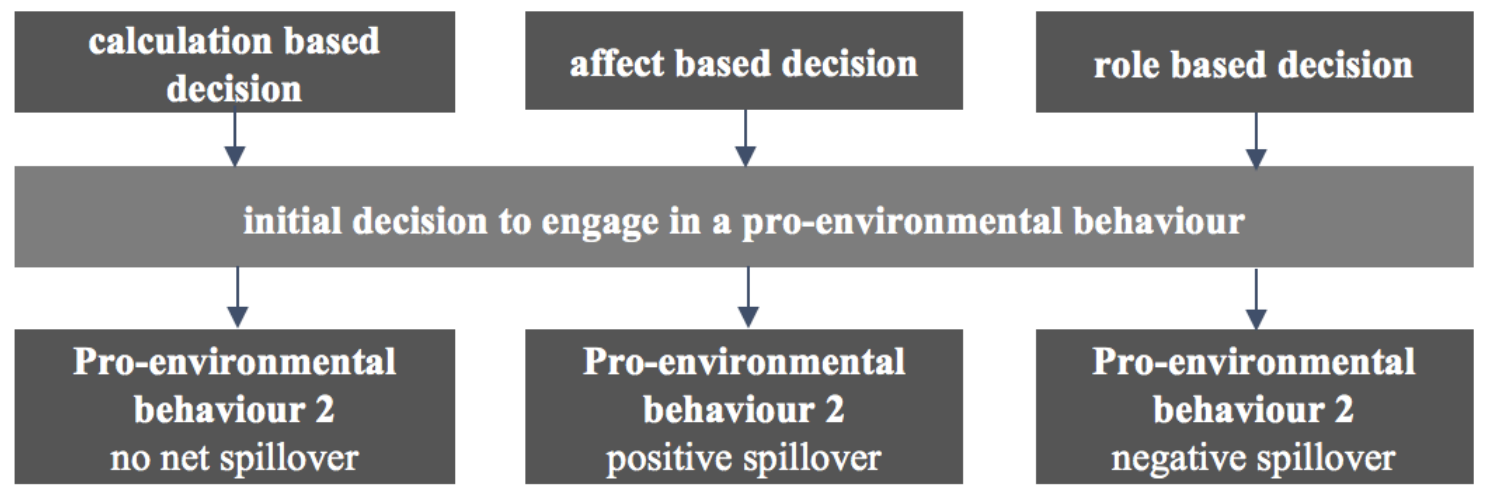

Figure 1: Theoretical framework illustrating simplified decisions modes on spillover; adapted from Truelove et al. (2014)

\subsubsection{Promoting, permitting \& purging strategies in the workplace}

Similar to Truelove et al.’s (2014) framework, Dolan and Galizzi’s (2015) suggest that spillover links an initial pro-environmental behaviour with a subsequent pro-environmental behaviour. More specifically, Dolan and Galizzi (2015) propose that pro-environmental behaviour A (initial behaviour) and pro-environmental behaviour B (subsequent behaviour) can be linked in three ways: promoting, permitting, and purging; processes that lead to positive spillover, negative spillover, and neutralisation 
of spillover (Dolan and Galizzi, 2015). They suggest that underlying motives link the behaviours at an unconscious or conscious level and build their framework based on existing mechanisms that are associated with spillover (Dolan and Galizzi, 2015). Thus, the 'promoting' strategy can be explained with cognitive dissonance theory (Festinger, 1957), foot-in-the-door effect (Burger, 1999), emotion carryover (Dolan and Galizzi, 2015) and other theories and will lead to positive spillover. The 'permitting' strategy can be explained with ego-depletion (Baumeister et al., 1998), moral licensing (Blanken et al., 2015), single action bias (Weber, 2006) and other theories and leads to negative spillover. The 'purging' strategy assumes an environmentally-unfriendly behaviour, which then leads to a pro-environmental behaviour through moral cleansing (Sachdeva et al., 2009) and other processes.

\subsubsection{Summary}

Both theoretical frameworks aim to explain spillover effects between different pro-environmental behaviours, which can be positive, negative or not occur at all. Although the frameworks proposed by Truelove et al. (2014) and Dolan and Galizzi (2015) differ, both have implications for spillover of pro-environmental behaviour in the workplace as they outline processes that may lead to spillover effects. The framework proposed by Truelove et al. (2014) can inform strategies and techniques of behaviour change interventions in workplaces. Instead, Dolan and Galizzi’s (2015) framework uncovers some of the mechanisms that may lead to pro-environmental behaviours in line with a behaviour change programme in an organisation (i.e. positive spillover), which is of interest for people designing effective behaviour change programmes in the workplace. Further research is needed to investigate the pathways that lead to spillover of pro-environmental behaviours as proposed by Truelove et al. (2014) and Dolan and Galizzi (2015).

\subsection{Contextual spillover}

As mentioned before, Nilsson et al. (2016) distingusih between behavioural spillover, contextual and temporal spillover. Contextual spillover - sometimes also found under the concept of border crossing (Uzzell and Räthzel, 2013) - describes spillover of pro-environmental behaviours between different settings; e.g. between home and work; or between work and home settings. A spillover effect between settings occurs when a pro-environmental behaviour in one context has a 'knock-on' effect on proenvironmental behaviours in another context (Littleford et al., 2014; Margetts and Kashima, 2017). For instance, when energy saving behaviour at home is subsequently followed by increased energy saving behaviours at work this is described as positive spillover between settings. Similar to spillover between behaviours, spillover between settings can also be negative, in which case the reverse effect occurs that is when energy saving behaviour at home leads to a decrease in energy saving behaviour at work. 


\subsection{Spillover between the home and the workplace settings}

Spillover effects between the workplace and the home settings have been investigated for a number of years. However, most studies have been focussing on work flexibility and stress (Hyland and Protta, 2016), happiness and well-being (Rodríguez-Muñoz et al., 2013) and work-family conflict (SanzVergel et al., 2015), but to a lesser extent for pro-environmental behaviours. More recently, emerging research has been examining potential spillover effects of pro-environmental behaviours and attitudes between the work and home settings. People spend a large amount of their time within their homes and workplaces (Klade et al., 2013), which is why understanding the potential for spillover between these contexts plays an important role in promoting more sustainable lifestyles.

A number of studies have researched predictors of 'green' employee behaviour in organisations and found that pro-environmental behaviour at home explains a reasonable share of pro-environmental behaviour at work (for a literature review of predictors of employee pro-environmental behaviour see Young et al., 2013 and Lo et al., 2012). For instance, Tudor et al. (2008) found that pro-environmental behaviours of employees at home determined their sustainable waste management behaviour which indicates a spillover effect from the home setting to the workplace. Thus, employees who already engage in pro-environmental behaviours at home are likely to also bring these behaviours to their workplace. In fact, research in human resource management even suggests that the organisations environmental reputation plays an increasingly important role for jobseekers (Renwick et al., 2013). This impels organisations to increase their efforts to provide environmentally friendly workplaces for their employees. However, very little research has been done to investigate the effects of an environmentally friendly workplace or behaviour change programmes at work have on employees' pro-environmental behaviour at home. To date, most research focuses on pro-environmental behaviour at home as a predictor of pro-environmental behaviour at work, but spillover effects can occur in both directions; i.e. from home to work and from work to home.

A study by Rashid and Mohammad (2011) found that employees, who were involved in the implementation of an environmental management system in their workplace, were also more likely to be involved in pro-environmental behaviours at home. In their study, the positive spillover effect between the workplace and the home was positively influenced by employee's identification with the organisation (Rashid and Mohammad, 2011). Similarly, environmental education programmes in organisations can also have an effect beyond pro-environmental behaviours at work. A case study analysis by the Scottish Government showed that exposure to environmental education at work and employees' commitment to the organisation's environmental values were key drivers of spillover from the workplace to other areas of life (Cox et al., 2012). On the other hand, employees' engagement in pro-environmental behaviours does not only have positive spillover effects on proenvironmental behaviours at home. Cox et al. (2012) report that some employees who complied with pro-environmental behaviours at work were less likely to engage in similar activities at home; thus, 
negative spillover occurred. According to Cox et al. (2012), these findings were more typical in larger organisations and when the employees agreed less with the organisation's corporate values.

\subsubsection{Border-crossing}

An alternative approach to cross-contextual spillover is the concept of 'border-crossing' (Uzzell and Rätsel, 2013). The term 'border-crossing' is proposed to describe the transfer of pro-environmental practises, in particular, from one setting (e.g. the workplace) to another setting (e.g. the home; Uzzell and Rätsel, 2013). According to Uzzell and Rätsel (2013: 19), "border-crossing takes into account that people are active agents, who negotiate their relations within and between the different areas in different ways at different times and places”. They argue that, in contrast to the spillover concept that suggests employees will copy behaviour from one setting (e.g. the workplace) to another setting (e.g. the home), the concept of border-crossing recognises employees understand a behaviour (e.g. at work) and then transfer it to another setting (e.g. the home) (Uzzell and Rätsel, 2013). In two case studies with organisations from the oil and car manufacturing industry they investigated the concept of border-crossing and identified several of characteristics of (e.g. physical border-crossing, temporal border-crossing, psychological border-crossing, and social and organisational border-crossing) and barriers to (e.g. disempowerment, conflicts, lack of influence, and identity) border-crossing (for a full report on the case studies see Uzzell and Rätsel, 2013). Although spillover between settings or crosscontextual spillover is currently the dominant conceptualisation, the concept of border-crossing constitutes an alternative view to the way employees 'transfer' pro-environmental behaviours from work to other life settings and vice versa which takes peoples agency into account.

\subsubsection{A theoretical framework of spillover between the workplace and home}

Nik Ramli and Naja (2012) propose a framework of positive spillover from the workplace to the home setting. Drawing from social identity theory, place attachment theory, and cognitive dissonance theory they suggest that spillover of pro-environmental behaviours goes through three stages: (1) formation of attitude and behaviour in the workplace, (2) the need to maintain one's behaviour consistent with one's attitudes and norms, and (3) performance of pro-environmental behaviour as a responsible community member (Nik Ramli and Naja, 2012). This model is mainly underpinned by the consistency theory that posits that "attitude, values and norm are what make the whole person - no matter where he or she is” (p. 1068) and complemented by factors such as management support and employees’ organisational identification (Nik Ramli and Naja, 2012).

\subsection{Spillover between the home and tourism/travelling settings}

Spillover between the home setting and tourism (e.g. holidays) or travelling settings is also a type of contextual spillover but it is less researched than spillovers between the work and home and vice versa (Nilsson et al., 2016). In the context of holiday decision making, Schütte and Gregory-Smith (2015) found a lack of spillover between the home and holiday settings when people were using 
neutralisation and mental accounting techniques to justify their unethical behaviour and to manage their negative emotions.

The above findings about negative spillover are consistent with those of Barr et al. (2010) and Hares et al. (2010). Barr et al. (2010) has identified distinct clusters of consumers who displayed different levels of greener lifestyles and (lack of) spillover between home and travel/holiday settings. This points out that spillover between these two domains is not straightforward due to various influencing factors such as values, attitudes, habits, disposable time and income. Overall, the potential spillover between home-based and tourism/travel-based environmental behaviours remains largely underresearched. Although Schütte and Gregory-Smith (2015) and Barr et al. (2010) investigated spillover effects between the home and leisure travelling, their findings could have implications for business travel as well. However, to our knowledge, spillover effects between the home or workplace to the business travel setting has not been investigated yet.

\subsection{Factors influencing spillover involving a workplace context}

The occurrence of spillover effects both positive and negative, as well as between behaviours and between settings is influenced by a number of factors. More recently, research has been focussing on identifying underlying factors of spillover effects. The aim is to gain a better understanding of what influences both positive and negative spillover effects. In the organisational context, the factors that influence spillover effects can have implications for the communication of pro-environmental behaviours and for the design and implementation of behaviour change programmes. In particular, a greater knowledge about factors that influence spillover effects can help promote positive spillover effects in order to create a greater impact of, for instance, behaviour change programmes in organisations. On the other hand, knowing about factors that make negative spillover more likely or prevent a positive spillover effect can help to recognise limitations certain behaviour change campaigns might have (Thøgersen and Crompton, 2009).

\subsubsection{Values, personal norms, and self-efficacy}

Drawing from theories explaining pro-environmental behaviours (e.g. theory of planned behaviour by Ajzen, 1991; value-belief-norm theory by Stern, 2000) several studies indicate that values, personal norms, and self-efficacy influence spillover, both between behaviours and settings. For instance, in a three-wave-panel study with Danish consumers Thøgersen and Ölander (2003) found a moderating effect of individual values and personal norms for positive spillover. They found that the likelihood of positive spillover was higher when people had a high priority for Schwartz's “universalism” values (Thøgersen and Ölander, 2013). Similarly, Steinhorst and Matthies (2016) identified personal norms as a predictor and moderator of positive spillover from energy saving behaviour to acceptability of policies. In another study, they found that positive spillover is mediated by personal norms and self- 
efficacy (Steinhorst et al., 2015). In line with this, a high personal norm for pro-environmental behaviour was found to have a moderating effect on the likelihood of spillover between similar proenvironmental behaviours (Thøgersen, 2004). Overall, these findings indicate that self-transcendent values moderate positive spillover whereas self-interest values inhibit positive spillover or might even lead to negative spillover. Although the studies above are not workplace specific, the findings can be transferred to the workplace context. Making employees' 'universalism' values and personal norms salient or promoting employees' self-efficacy could increase positive spillover effects between proenvironmental behaviours at work and from the workplace into the home setting.

\subsubsection{Organisational values}

Employees' identification with organisational values also influences the occurrence of spillover effects, both between behaviours in the workplace and between the work setting and other areas of life. An overlap between the employee's and the organisations values can promote positive spillover whereas incongruity can lead to negative spillover. In a case study analysis for the Scottish Government, Cox and colleagues (2012) found that shared values between organisations and employees and employee's commitment to 'green' organisational values leads to positive spillover, whereas a lack of shared values and commitment to the organisation's green values can lead to a lack of spillover or even negative spillover. Thus, the employee-organisation-value fit as well as the organisations' communication and realisation of pro-environmental values can lead to positive spillover effects and promote sustainable lifestyles at work and beyond the workplace.

\subsubsection{Framing of behaviour and communication}

The way pro-environmental behaviours are framed and communicated also has a great effect on potential spillover effects. When promoting pro-environmental behaviours, monetary rewards are a popular tool (Abrahamse et al., 2005). However, financial framing of pro-environmental behaviour makes self-interest values more salient, whereas environmental framing makes self-transcendent values - which are associated with pro-environmental values - more salient (Evans et al., 2012). For instance, when self-interest was prompted right after self-transcendent motives had been used, environmental effect was neutralized and no spillover effect was detected (Evans et al., 2012). Steinhorst and Matthies (2016), for example, found a spillover effect only in the environmental frame condition and not in the financial framing condition. Consequently, it is important to consider potential spillover effects that the framing of a social marketing campaign in an organisation or for a wider context can have. Although financial framing might often seem to be the easiest and most promising way to encourage environmentally friendly behaviours among employees, the studies suggest that there is a downside. Thus, communications using environmental framing might have more positive effects on employees’ pro-environmental behaviour in the long run in comparison to financial framing. 


\subsubsection{Environmental identity}

'Who am I?' - If the answer is 'an environmentally sustainable person', positive spillover effects between behaviours and across contexts is more likely compared to people that do not see environmental sustainability as a part of their identity (Whitmarsh and O’Neill, 2010). Environmental identity is a determinant for pro-environmental behaviour in general but also for positive spillover effects (Whitmarsh and O’Neill, 2010). For instance, van der Werff et al. (2014a, 2014b) showed in several studies that environmental identity acts as an antecedent of pro-environmental behaviours whilst also being influenced by past pro-environmental behaviour. In line with this, Lacasse (2016) showed past pro-environmental behaviour strengthens people's environmental self-identity, which then leads to greater concern for climate change. This indicates that environmental identity is an underlying factor of spillover, which is in line with self-perception theory. An experimental study among US students on recycling behaviour found that environmental identity mediated spillover between recycling behaviour and support for a green fund (Truelove et al., 2016). In the organisational context, the values-identity-personal-norms (VIP) model integrates identity theory with value and personal norm theories to explain pro-environmental behaviour at work (Ruepert et al., 2016). In a study with 618 employees, Ruepert et al. (2016) found that environmental identity mediated biospheric values and personal norms which in turn affected pro-environmental behaviour at work. Hence, environmental identity plays an important role for facilitating positive spillover. These findings can be utilised for communication and social marketing campaigns in organisations. Based on Lacasse's (2016) findings it could be inferred that labelling people as being “environmentalists" would enhance their environmental identity and that, thus, have a positive effect on the intention to act pro-environmentally in the future.

\subsection{Methodological approaches to researching spillover}

The spillover phenomenon has been investigated so far drawing on a rich array of methods inclusive of quantitative, qualitative and mixed methods. The choice of the most appropriate method should be based on the assessment of key assumptions of the spillover effect: a) the spillover effect presumes a change in one behaviour leads to changes in other behaviours; and b) the spillover effect occurs in a timely order as the initial behaviour influences other behaviours at a later point. Thus, the relationship of pro-environmental behaviours - between different behaviours, over time, or between different settings - should always be paramount to the chosen methodological approach.

\subsection{Quantitative methods approach}

Quantitative methods are most commonly used to investigate the spillover effect and they mainly include correlational, longitudinal cross-lagged designs and experimental and quasi-experimental approaches. A correlational approach is reflected in a research design that collects data on people's 
pro-behaviours at one time point (e.g. through a survey) and then investigates the relationship between these behaviours. For example, in a survey with US residents Thøgersen and Noblet (2012) investigated the correlation between 'every-day green behaviours' and the acceptance of wind power. Similarly, a survey by Lauren et al. (2016) investigated the correlation between easy and difficult water saving behaviours while also examining the mediating effect of self-efficacy of these behaviours. A survey conducted by Littleford et al. (2014) with employees of local government organisations examined how energy saving behaviours at home and at work are correlated. Although correlational studies are popular and the research design is low in cost, one might critique that correlational data is not as meaningful to investigate spillover as timely data collection (e.g. longitudinal studies) or experimental designs. While correlational data can provide initial indications of types of spillover effects or potential underlying factors influencing spillover, experimental and longitudinal data collection should be the preferred approach when using quantitative methods.

Longitudinal studies observe behaviour over a period of time. For instance, studies using a longitudinal cross-lagged design measure the 'organic' development of pro-environmental behaviours over time. In most cases, the focus is on the observation of the influence of an initial behaviour (e.g. recycling at work) on a second behaviour (e.g. energy use at work) at a later time point. If the second behaviour increases, this is interpreted as positive spillover; whereas if it decreases, a negative spillover effect occurs. If there is no relationship between behaviours over time, this indicates a lack of spillover or no net spillover. A study using this methodological approach was conducted by Thøgersen and Ölander (2003). By using a three-wave cross-lagged panel, they investigated how proenvironmental behaviours (i.e. organic consumption, recycling and transport behaviour) would influence each other over a period of two years. Another approach for using a longitudinal design is by observing the effect a behaviour change intervention or a policy change has on pro-environmental behaviours compared to behaviour prior to the intervention. For instance, Thomas et al. (2016) analysed longitudinal data from a nationally-representative sample $(\mathrm{n}=17,636$; Wales, England, and Scotland) to investigate spillover effects from the single-use carrier bag charge in Wales to six other pro-environmental behaviours. Over the course of three years they found that the use of own shopping bags increased in Wales compared to Scotland and England after the introduction of the charge and that it was also linked to the increase of six other pro-environmental behaviours (Thomas et al., 2016); which is interpreted as a positive spillover effect. However, the increase of three of the proenvironmental behaviours was weaker in Wales than in England and Scotland (Thomas et al., 2016). But there was a significant increase in pro-environmental attitudes, which indicates a positive spillover effect from the increased own bag use due to the carrier bag charge to pro-environmental attitudes (Thomas et al., 2016).

Lastly, spillover has been investigated through studies employing experimental and quasiexperimental designs, which focus on the causal effects between independent and dependent variables. 
For example, Evans et al. (2012) investigated the cause-effect relationship between information provided by an intervention and its effect on behavioural spillover. The information given to participants (independent variable) was manipulated so that one group received environmental information about car-sharing and the other group received financial information about car-sharing (Evans et al., 2012). Ultimately, the former group showed higher recycling behaviour (dependent variable), which was interpreted as positive spillover, compared to the group that received financial information (Evans et al, 2012). Based on these findings, Evans et al. (2012) conclude that environmental framing of a message makes self-transcendent values salient which then leads to positive spillover. While this example concurs that cause-effect relationships could be explored via experimental designs (ensuring a high internal validity), they cannot capture the multitude and complexity of all the factors that influence environmental spillover in the 'real world'. Steinhorst and Matthies (2016) conducted a longitudinal field experiment in order to account for both cause-effect relationships and 'real world' complexity. In their online survey, clients of a German energy provider were randomly assigned to either receive financially or environmentally framed energy saving tips or to a control group, which did not receive any information (Steinhorst and Matthies, 2016). In line with Evans et al.'s (2012) findings, the study showed people in the environmental framing condition increased their energy saving behaviour and also increased their acceptance towards low carbon policies, which is interpreted as a positive spillover effect (Steinhorst and Matthies, 2012). People in the financial framing condition, on the other hand, showed an increase in their energy saving behaviour but not in their acceptance towards low carbon policies (Steinhorst and Matthies, 2012).

Overall, quantitative methods are currently the most commonly used approach to examine spillover effects. And, as shown above, there are a number of approaches to measure spillover effects with quantitative data, which differ in costs (time and resources), causality assessment, and consideration of 'real world' complexity. Although correlational studies are a suitable way to test initial ideas and directions for further research, future research should focus on longitudinal data and integration of experimental designs in order to measure spillover (Lanzini andThøgersen, 2014; Wells et al., 2016; Dolan and Galizzi, 2015; Porrtinga et al., 2013). Furthermore, the integration of qualitative and quantitative methods into mixed methods designs could be informative for a more in depth understanding of spillover and particularly motivations and other factors that influence spillover effects.

\subsection{Qualitative methods approach}

Qualitative methods have been also used, as an alternative to quantitative approaches, to explore proenvironmental behaviours and their (lack of) spillover. For example, Schütte and Gregory-Smith (2015) have examined the cognitive and emotional processes related to lack of spillover between sustainable behaviours at home and holiday-related behaviours using semi-structured interviews. Other studies have employed a multi-method qualitative approach such as Dumitru et al.’s (2016) 
study that used documents, interviews and focus groups. Their comparison of two organisations (i.e. a green energy company and a university) revealed only a spillover of values from the green energy company to its employees; this was not noticed in the case of the employees of public university organisation (Dumitru et al., 2016).

An alternative qualitative approach is that of Uzzell and Räthzel (2013) who applied an integrative ethnographic and interpretative method to explore contextual spillover between the workplace and home, which they refer to as 'border crossing'. Their study used life-history interviews with employees, which implied interviewees acting 'as an independent narrator of her/his life trajectory and personal subjectivity’ (Uzzell and Räthzel, 2013: 11).

Overall, while qualitative methods have been used both to probe and gain a more in-depth understanding of environmental behaviours and spillover, their use alone is not sufficient to capture accurately actual behaviour and longitudinal aspects of spillover. Therefore, a more comprehensive approach to researching spillover would use mixed methods approach.

\subsection{Mixed methods}

Mixed methods designs allow the collection of diverse perspectives on the research topic by using both quantitative and qualitative data (Teddlie and Tashakkori, 2003). Mixed methods in spillover research are rare, partly because it is a very time consuming approach.

An example of a mixed-methods study was conducted by Barr et al. (2010), who looked at the spillover between pro-environmental behaviours at home and away/on holiday. They used an on-street survey that led to a clustering of consumers' lifestyles, followed by focus group discussions with each of the identified consumer clusters (Barr et al., 2010). Another example is a study on the introduction of the plastic bag charge in Wales and its spillover into other pro-environmental behaviours (Poortinga et al., 2016). Using a mixed-methods and longitudinal approach, Poortinga et al. (2016) examined attitudinal and behaviour changes following the English plastic bag charges that was introduced in 2015. They integrated a longitudinal survey, a longitudinal diary-interview study, and a longitudinal supermarket observation study conducted in three countries (England, Wales, and Scotland) to uncover potential spillover effects from the introduction of the plastic bag charge (Poortinga et al., 2016). The findings showed people became more supportive of the plastic bag charge as well as of other charges to reduce waste; which is interpreted as a positive spillover effect (Poortinga et al., 2016). Poortinga et al. (2016) also concluded that using a mixed-methods and longitudinal approach the findings constitute a comprehensive and robust evaluation of attitudinal and behavioural impact of a policy change such as the plastic bag charge in England. 


\subsection{Policy and managerial implications}

Researchers and policy makers have been particularly interested in the idea of accelerating sustainable lifestyles by campaigning for simple and low impact environmental behaviours, which could have a ‘knock-on’ effect on other potentially more difficult pro-environmental behaviours. However, encouraging spillover across various aspects of one's life, particularly with regards to more difficult and complex behaviours, is not an easy task to achieve (Thøgersen and Crompton, 2009). Despite various challenges, measures could be taken to increase the likelihood of spillover. For example, past research (Bratt, 1999; Thøgersen, 2004) has shown that spillover is more likely to happen between similar (or perceived to be similar) behaviours. Thus, both governmental campaigns targeting the general public and organization-based interventions targeting employees should focus on making clear-cut links between the behaviors that they would target and expect to engender spillover for (Thøgersen 2004).

In relation to environmental communications, Thøgersen and Crompton (2009) consider that contextual spillover is more likely to be generated but the use of communications or interventions that allude to individuals' environmental values and concerns rather than financial rewards and status signalling. These findings are complemented by those of Steinhorst and Matthies (2016) who examined the long-term spillover effects of electricity saving behaviour. Following the study results, they recommended that information campaigns targeting individuals with strong personal ecological norms should use environmental framing (CO2) rather than monetary framing (money) (Steinhorst and Matthies, 2016). This will encourage positive spillover into the acceptance of other environmental policy measures. However, for the individuals with weak personal ecological norms, the environmental framing had a negative effect and thus further research is need in terms of effective design and communications for this group of people (Steinhorst and Matthies, 2016).

Moreover, Thøgersen and Noblet's (2012) study on consumers' acceptance of spillover to wind power concluded that information should be provided via social marketing campaigns to increase environmental awareness and concern. Particularly, they consider the focus should be on encouraging individuals to perform 'regular' or 'more familiar' green behaviours, and in time this action-based learning could lead to positive spillover in other environmental contexts and behaviours (Thøgersen and Noblet, 2012).

Another avenue for potentially achieving spillover of environmental behavior is the appeal to and development of one's environmental identity. A study among US students on recycling behaviour found that environmental identity mediated spillover between recycling behaviour and support for a green fund (Truelove et al., 2016). However, this relationship and the influence of identity, in general, can be quite complex and at times unfavourable. For example, Truelove et al. (2016) also uncovered that for the Democrats in their study (who are expected to support pro-environmental behaviour as 
part of their political identity) recycling behaviour had a negative effect on environmental identity (i.e. lower environmental identity), which in turn decreased support for a green fund, indicating negative spillover. Therefore, caution should be exerted when developing social marketing interventions and communications based on the 'environmental identity' psychological concept.

While in section 4 a range of individual and organisational factors that can foster environmental spillover were mentioned, some researchers caution that these might not be always effective in practice. For example, it is considered that social norms are expected to have a positive impact but such an approach would be "only useful when a majority of the target population actually performs the desired pro-environmental behaviour, which is often not the case for the more difficult" (Thøgersen and Crompton, 2009: 156) and hence spillover is less likely to occur. Therefore, emphasising the exceptional behaviour rather than the normative existent behaviour is needed.

Therefore, overall, a range of communications and behaviour change approaches could be used in relation to engendering spillover between the home and workplace settings, but these should be carefully assessed in relation to its audience, targeted behaviours and contexts.

Implications for the organisational context include suggestions for communicating pro-environmental behaviours in the organisation and framing of messages. In line with findings from Steinhorst and Matthies' (2016) and Evans et al.’s (2012) studies, organisations should be cautious to uses financial framing and rewards to promote pro-environmental behaviours among their employees as these are likely to lead to no or negative spillover. Furthermore, in the organisational context a number of organisational factors can influence both positive and negative spillover. For instance, factors such as organisational culture, management support, and the employees' identification with the organisation can promote positive spillover between pro-environmental behaviours at work (Lo et al., 2012; Cox et al., 2012). A case study by the Scottish Government found that employees' commitment to ecological organisational values lead to positive spillover between pro-environmental behaviours in the workplace but also between work and home (e.g. fuel efficient driving and recycling) (Cox et al., 2012). On the other hand, a lack of employees' commitment to the organisation's green values led to a lack of or even negative spillover (Cox et al., 2012).

Additionally, one of the biggest policy makers' challenges in normalizing spillover, both within and across contexts, is individuals' choice of lifestyles. As Barr et al. (2010) pointed out, the motivations and behavioural spillover predisposition of some individuals will differ according to their lifestyle choices. Therefore, generic interventions and marketing communications approaches might require some levels of tailoring according to the context and behaviours targeted for spillover. Moreover, Barr et al. (2010) concluded that certain contexts, such as holidays and travelling, are less likely to witness spillover because of hedonism, convenience preferences and neutralisation tendencies. This suggests 
that additional research is needed to understand how these psychological mechanisms can be counteracted and future findings might inform practice, both at policy and organisational levels.

The present chapter has discussed the concept of spillover in pro-environmental behaviour research. More particularly, it provided an overview of the current spillover literature and its relevance to environmentally friendly behaviours and the workplace. Additionally, this chapter also critically examined methodological approaches to investigate spillover effects both between behaviours and between settings. Lastly, the present chapter considered the implications of both positive and negative spillover effects for social marketing campaigns and behaviour change programmes that promote pro-environmental behaviours in organisations. As outlined throughout the chapter, there are a number of individual factors (e.g. identity, norms) as well as contextual and behavioural factors (e.g. similarity between behaviours and/or settings) that influence spillover effects. For organisations that want to promote pro-environmental behaviours among their employees, it is important to consider these factors as they may endorse or inhibit behaviour change programmes and the organisation's environmental impact. Organisations that aim to promote pro-environmental behaviours among their employees might, therefore, prefer to promote those behaviour which are similar to behaviours already perforemed by their employees at home.

\subsection{References}

Abrahamse, W., Steg, L., Vlek, C. and Rothengatter, T. (2005), 'A review of intervention studies aimed at household energy conservation', Journal of Environmental Psychology, 25 (3), 273-291.

Acs, Z. J., Audretsch, D. B. and Lehmann, E. E. (2009), 'The knowledge spillover theory of entrepreneurship', Small Business Economics, 32, 15-30.

Austin, A., Cox, J., Barnett, J. and Thomas, C. (2011), 'Exploring catalyst behaviours: Full Report', a report to the Department for Environment, Food and Rural Affairs, Brook Lyndhurst for Defra, London. Available from: http://randd.defra.gov.uk/Default.aspx?Module=More\&Location=None\&ProjectID=16324 [Accessed 21 May 2017].

Baumeister, R. F., Bratslavsky, E., Muraven, M. and Tice, D. M. (1998), 'Ego depletion: is the active self a limited resource?', Journal of Personality and Social Psychology, 74 (5), 1252-1265.

Barr, S., Shaw, G., Coles, T. and Prillwitz, J. (2010), '“A holiday is a holiday’: practicing sustainability, home and away', Journal of Transport Geography, 18 (3), 474-481. 
Bem, D. J. (1972), 'Self-perception theory', Advances in Experimental Social Psychology, 6, 1-62.

Blanken, I., van de Ven, N. and Zeelenberg, M. (2015), 'A Meta-Analytic Review of Moral Licensing', Personality and Social Psychology Bulletin, 41 (4), 540-558.

Bratt, C. (1999), 'Consumers environmental behavior: Generalized, sector-based, or compensatory?', Environment and Behavior, 31, 28-44.s[ep?

Burger, J. M. (1999), 'The foot-in-the-door compliance procedure: a multiple-process analysis and review', Personality and Social Psychology Review, 3 (4), 303-325.

Carrico, A. R. and Riemer, M. (2011), 'Motivating energy conservation in the workplace: An evaluation of the use of group-level feedback and peer education', Journal of Environmental Psychology, 31 (1), 1-13.

Carrus, G., Passafaro, P. and Bonnes, M. (2008), 'Emotions, habits and rational choices in ecological behaviours: The case of recycling and use of public transportation', Journal of Environmental Psychology, 28 (1), 51-62.

Cialdini, R. B., Trost, M. R. and Newsom, J. T. (1995), 'Preferences for Consistency: The Development of a Valid Measure and the Discovery of Surprising Behavioural Implications', Journal of Personality and Social Psychology, 69 (2), 318-328.

Cox, A., Higgins, T., Gloster, R., Foley, B. and Darnton, A. (2012), 'The Impact of Workplace Initiatives on Low Carbon Behaviours', a report to the Schottish Government. Available from: www.scotland.gov.uk/socialresearch [Accessed: 21 May 2017].

Defra (2008), 'Framework for pro-environmental behaviours', report for the Department for Environment, Food and Rural Affairs. Available from:

https://www.gov.uk/government/uploads/system/uploads/attachment_data/file/69277/pb13574behaviours-report-080110.pdf [Accessed 21 May 2017].

Dolan, P. and Galizzi, M. M. (2014), 'Because I'm Worth It: A Lab-Field Experiment on the Spillover Effects of Incentives in Health', CEP Discussion Papers. Available from: at http://ideas.repec.org/p/cep/cepdps/dp1286.html [Accessed: 21 May 2017].

Dolan, P. and Galizzi, M. M. (2015), 'Like ripples on a pond: Behavioral spillovers and their implications for research and policy', Journal of Economic Psychology, 47, 1-16.

Dumitru, A., De Gregorio, E., Bonnes, M., Bonaiuto, M., Carrus, G., Garcia-Mira, R. and Maricchiolo, F. (2016), 'Low carbon energy behaviors in the workplace: A qualitative study in Italy and Spain' Energy Research \& Social Science, 13, 49-59. 
Evans, L., Maio, G. R., Corner, A., Hodgetts, C. J., Ahmed, S. and Hahn, U. (2012), 'Self-interest and pro-environmental behaviour', Nature Climate Change, 3 (2), 122-125.

Festinger, L. (1957), A Theory of Cognitive Dissonance, Stanford, CA, USA: Stanford University Press.

Gregory-Smith, D., Wells, V. K., Manika, D. and Graham, S. (2015), 'An environmental social marketing intervention among employees: assessing attitude and behaviour change', Journal of Marketing Management, 31 (3-4), 336-377.

Gregory-Smith, D., Smith, A. and Winklhofer, H. (2013), 'Emotions and dissonance in ‘ethical’consumption choices’, Journal of Marketing Management, 29 (11-12), 1201-1223.

Grunberg, L., Moore, S. and Greenberg, E. (1998), 'Work stress and problem alcohol behavior : a test of the spillover model', Journal of Organizational Behavior, 19 (5), 487-502.

Han, S., Lerner, J. S. and Keltner, D. (2007), 'Feelings and consumer decision making: The appraisaltendency framework', Journal of consumer psychology, 17 (3), 158-168.

Hares, A., Dickinson, J. and Wilkes, K. (2010), 'Climate change and the air travel decisions of UK tourists', Journal of Transport Geography, 18 (3), 466-473.

Hope, A. L., Jones, C. R., Webb, T. L., Watson, M. T., and Kaklamanou, D. (2017). The Role of Compensatory Beliefs in Rationalizing Environmentally Detrimental Behaviors. Environment and Behavior.

Hyland, M., and Prottas, D. (2016). Looking at spillover from both sides: an examination of work and home flexibility and permeability. Community, Work \& Family, 8803 (June), 1-20.

Kaklamanou, D., Jones, C. R., Webb, T. L. and Walker, S. R. (2013), 'Using Public Transport Can Make Up for Flying Abroad on Holiday: Compensatory Green Beliefs and Environmentally Significant Behavior', Environment and Behavior, 47 (2), 184-204.

Klade, M., Mert, W., Seebacher, U. and Schultz, I. (2013), 'Sustainable behaviour at work and in private life: the contribution of enterprises', International Journal of Innovation and Sustainable Development (IJISD), 7 (4), 321-332.

Klöckner, C. A., Nayum, A. and Mehmetoglu, M. (2013), 'Positive and negative spillover effects from electric car purchase to car use' Transportation Research Part D: Transport and Environment, 21, 32-38. 
Lacasse, K. (2016),'Don't be satisfied, identify! Strengthening positive spillover by connecting proenvironmental behaviors to an “environmentalist” label.', Journal of Environmental Psychology, 48, 149-158.

Lanzini, P. and Thøgersen, J. (2014), 'Behavioural spillover in the environmental domain: An intervention study', Journal of Environmental Psychology, 40, 381-390.

Lauren, N., Fielding, K. S., Smith, L. and Louis, W. (2016), 'You did, so you can and you will: Selfefficacy as a mediator of spillover from easy to more difficult pro-environmental behaviour', Journal of Environmental Psychology. 48, 191-199.

Laury, S. K. and Taylor, L. O. (2008), 'Altruism spillovers: Are behaviors in context-free experiments predictive of altruism toward a naturally occurring public good?', Journal of Economic Behavior \& Organization, 65 (1), 9-29.

Lee, S., Davis, K. D., Neuendorf, C., Grandey, A., Lam, C. B. and Almeida, D. M. (2016), 'Individual-and organization-level work-to-family spillover are uniquely associated with hotel managers' work exhaustion and satisfaction', Frontiers in Psychology, 7.

Lerner, J. S., Small, D. A. and Loewenstein, G. (2004), 'Heart strings and purse strings carryover effects of emotions on economic decisions', Psychological science, 15 (5), 337-341.

Littleford, C., Ryley, T. J. and Firth, S. K. (2014), 'Context, control and the spillover of energy use behaviours between office and home settings', Journal of Environmental Psychology, 40, 157-166. Lo, S. H., Peters, G.-J. Y. and Kok, G. (2012), ‘A Review of Determinants of and Interventions for Proenvironmental Behaviors in Organizations’, Journal of Applied Social Psychology, 42 (12), 29332967.

Margetts, E. A. and Kashima, Y. (2017), 'Spillover between pro-environmental behaviours: The role of resources and perceived similarity', Journal of Environmental Psychology, 49, 30-42.

Merritt, A. C., Effron, D. A. and Monin, B. (2010), 'Moral self-licensing: When being good frees us to be bad', Social and personality psychology compass, 4 (5), 344-357.

Meijers, M. H. C., Verlegh, P. W. J., Noordewier, M. K. and Smit, E. G. (2015), 'The dark side of donating: how donating may license environmentally unfriendly behavior', Social Influence, 10 (4), 250-263.

Muster, V. (2011), 'Companies Promoting Sustainable Consumption of Employees', Journal of Consumer Policy, 34 (1), 161-174. 
Nik Ramli, N. A. R. and Naja, M. (2012), 'A Discussion of Underlying Theories Explaining the Spillover of Environmentally Friendly Behavior Phenomenon', Procedia - Social and Behavioral Sciences, 50 (July), 1061-1072.

Nilsson, A., Bergquist, M. and Schultz, W. P. (2016), 'Spillover effects in environmental behaviors, across time and context: a review and research agenda', Environmental Education Research, $\mathbf{4 6 2 2}$ (November), 1-17.

Norton, T. A., Parker, S. L., Zacher, H. and Ashkanasy, N. M. (2015), ‘Employee Green Behavior: A Theoretical Framework, Multilevel Review, and Future Research Agenda', Organization \& Environment, 28 (1), 103-125.

Ones, D. S. and Dilchert, S. (2012), 'Employee Green Behaviours', in Susan E. Jackson, Deniz. S. Ones, \& Stephan Dilchert (eds.), Managing Human Resources for Environmental Sustainability, San Francisco: Jossey-Bass, pp. 191-202.

Peters, A., Sonnberger, M., Dütschke, E. and Deuschle, J. (2012), 'Theoretical perspective on rebound effects from a social science point of view'. Working paper to prepare empirical psychological and sociological studies in the REBOUND project, Sustainability and Innovation. Vol. S 2, Karlsruhe: Fraunhofer ISI.

Poortinga, W., Sautkina, E., Thomas, G.O. and Wolstenholme, E. (2016), 'The Englisch plastic bag charge: Changes in attitudes and behaviour', Cardiff: Welsh School of Architecture/ School of Psychology, Cardiff University. Available from:

http://orca.cf.ac.uk/94652/1/Cardiff_University_Plastic_Bag_Report_A4\%20(final\%20proof).pdf [Accessed: 29 June 2017].

Rashid, N.R.N. and Mohammad, N., (2011). 'Spill Over of Environmentally Friendly Behaviour Phenomenon: The Mediating Effect of Employee Organizational Identification', OIDA International Journal of Sustainable Development, 2 (12), 29-42.

Renwick, D. W. S., Redman, T. and Maguire, S. (2013), 'Green Human Resource Management: A Review and Research Agenda', International Journal of Management Reviews, 15 (1), 1-14.

Rodríguez-Muñoz, A., Sanz-Vergel, A. I., Demerouti, E. and Bakker, A. B. (2014), 'Engaged at work and happy at home: A spillover-Crossover model’, Journal of Happiness Studies, 15 (2), 271-283.

Ruepert, A., Keizer, K., Steg, L., Maricchiolo, F., Carrus, G., Dumitru, A., ... Moza, D. (2016), 'Environmental considerations in the organizational context: A pathway to pro-environmental behaviour at work', Energy Research and Social Science, 17, 59-70. 
Sachdeva, S., Iliev, R. and Medin, D. L. (2009), 'Sinning saints and saintly sinners: The paradox of moral self-regulation', Psychological Science, 20 (4), 523-528.

Sanz-Vergel, A. I., Rodríguez-Muñoz, A. and Nielsen, K. (2015), 'The thin line between work and home: The spillover and crossover of daily conflicts', Journal of Occupational and Organizational Psychology, 88 (1), 1-18.

Schütte, L. and Gregory-Smith, D. (2015), 'Neutralisation and Mental Accounting in Ethical Consumption: The Case of Sustainable Holidays', Sustainability, 7, 1-14.

Sorrell, S., Dimitropoulos, J. and Sommerville, M. (2009), 'Empirical estimates of the direct rebound effect: A review', Energy Policy, 37 (4), 1356-1371.

Steg, L. and Vlek, C. (2009), 'Encouraging pro-environmental behaviour: An integrative review and research agenda' Journal of Environmental Psychology, 29 (3), 309-317.

Steinhorst, J. and Matthies, E. (2016), 'Monetary or environmental appeals for saving electricity? Potentials for spillover on low carbon policy acceptability’, Energy Policy, 93, 335-344.

Sykes, G. M. and Matza, D. (1957), 'Techniques of Neutralization: A Theory of Delinquency', American Sociological Review, 22 (6), 664-670.

Teddlie, C. and Tashakkori, A. (2003), 'Major Issues and Controversies in the Use of Mixed Methods in the Social and Behavioural Sciences', in Abbas Tashakkori \& Charles Teddlie (eds), Handbook of Mixed Methods in Social \& Behavioural Resaerch, $2^{\text {nd }}$ ed., London, UK: SAGE Publications Ltd, pp. $3-50$.

Thøgersen, J. (1999), 'Spillover processes in the development of a sustainable consumption pattern', Journal of Economic Psychology, 20 (1), 53-81.

Thøgersen, J. (2004), 'A cognitive dissonance interpretation of consistencies and inconsistencies in environmentally responsible behavior', Journal of Environmental Psychology, 24 (1), 93-103.

Thøgersen, J. and Crompton, T. (2009)' ,Simple and Painless? The Limitations of Spillover in Environmental Campaigning', Journal of Consumer Policy, 32 (2), 141-163.

Thøgersen, J. and Noblet, C. (2012), 'Does green consumerism increase the acceptance of wind power?' Energy Policy, 51, 854-862.

Thøgersen, J. and Ölander, F. (2003), 'Spillover of environment-friendly consumer behaviour', Journal of Environmental Psychology, 23 (3), 225-236. 
Thomas, G. O., Poortinga, W. and Sautkina, E. (2016), 'The Welsh Single-Use Carrier Bag Charge and behavioural spillover', Journal of Environmental Psychology, 47, 126-135.

Tiefenbeck, V., Staake, T., Roth, K. and Sachs, O. (2013), 'For better or for worse? Empirical evidence of moral licensing in a behavioral energy conservation campaign', Energy Policy, 57, 160171.

Truelove, H. B., Carrico, A. R., Weber, E. U., Raimi, K. T. and Vandenbergh, M. P. (2014), 'Positive and negative spillover of pro-environmental behavior: An integrative review and theoretical framework', Global Environmental Change, 29, 127-138.

Truelove, H. B., Yeung, K. L., Carrico, A. R., Gillis, A. J. and Raimi, K. T. (2016), 'From plastic bottles to policy support: An experimental test of pro-environmental spillover', Journal of Environmental Psychology, 46, 55-66.

Tudor, T. L., Barr, S. W. and Gilg, A. W. (2008), 'A novel conceptual framework for examining environmental behavior in large organizations: A case study of the Cornwall National Health Service (NHS) in the United Kingdom', Environment and Behavior, 40 (3), 426-450.

Uzzell, D. and Räthzel, N. (2013), 'Modelling agents and organisations to achieve transition to a low carbon Europe', D5.3: Final Report on the study of Everyday Environmental Strategies and Practices in Shell UK Ltd and AB Volvo, Umeå, Sweden.

van der Werff, E., Steg, L. and Keizer, K. (2014a), 'Follow the signal: When past pro-environmental actions signal who you are', Journal of Environmental Psychology, 40, 273-282.

van der Werff, E., Steg, L. and Keizer, K. (2014b), 'I Am What I Am, by Looking Past the Present: The Influence of Biospheric Values and Past Behavior on Environmental Self-Identity', Environment and Behavior, 46 (5), 626-657.

Weber, E. U. (2006), 'Experience-based and description-based perceptions of long-term risk: Why global warming does not scare us (yet)', Climatic Change, 77 (1-2), 103-120.

Wells, V. K., Taheri, B., Gregory-Smith, D. and Manika, D. (2016), 'The role of generativity and attitudes on employees home and workplace water and energy saving behaviours', Tourism Management, 56, 63-74.

Westman, M. (2002), 'Crossover of stress and strain in the family and in the workplace', in Pamela L. Perrewe and Dan Ganster (eds.), Research in occupational stress and well-being, $2^{\text {nd }}$ ed., JAI Press/Elsevier Science, pp. 143-18. 
Whitmarsh, L. and O’Neill, S. (2010), ‘Green identity, green living? The role of pro-environmental self-identity in determining consistency across diverse pro-environmental behaviours', Journal of Environmental Psychology, 30 (3), 305-314.

Winterich, K. P., Han, S. and Lerner, J. S. (2010), 'Now that I'm sad, it's hard to be mad: The role of cognitive appraisals in emotional blunting', Personality and Social Psychology Bulletin, 36 (11), 1467-1483.

Young, C. W., Davis, M., McNeill, I. M., Malhotra, B., Russell, S., Unsworth, K. and Clegg, C. W. (2013),' Changing behaviour: Successful environmental programmes in the workplace', Business Strategy and the Environment, 24, 689-703. 